\title{
A PRÁTICA OBSTÉTRICA DA ENFERMEIRA NO PARTO INSTITUCIONALIZADO: UMA POSSIBILIDADE DE CONHECIMENTO EMANCIPATÓRIO ${ }^{1}$
}

\author{
Maysa Luduvice Gomes², Maria Aparecida Vasconcelos Moura³, Ivis Emília de Oliveira Souza
}

\begin{abstract}
${ }^{1}$ Artigo extraído da tese - A prática obstétrica da enfermeira no parto institucionalizado: uma possibilidade de conhecimento emancipatório, apresentada ao Programa de Pós-Graduação em Enfermagem da Escola de Enfermagem Anna Nery (EEAN) da Universidade Federal do Rio de Janeiro (UFRJ), em 2011.

${ }^{2}$ Doutora em Enfermagem. Professora Assistente do Departamento de Enfermagem Materno-Infantil da Faculdade de Enfermagem da Universidade do Estado do Rio de Janeiro. Rio de Janeiro, Rio de Janeiro, Brasil. E-mail: maysa.luduvice@ gmail.com

${ }^{3}$ Doutora em Enfermagem. Professora Associado III do Departamento de Enfermagem-Materno Infantil da EEAN/UFRJ. Rio de Janeiro, Rio de Janeiro, Brasil. E-mail: maparecidavas@yahoo.com.br

${ }^{4}$ Doutora em Enfermagem. Professora Titular do Departamento de Enfermagem-Materno Infantil da EEAN/UFRJ. Rio de Janeiro, Rio de Janeiro, Brasil. E-mail: ivis@uol.com.br
\end{abstract}

RESUMO: Pesquisa qualitativa, que objetivou analisar os sentidos atribuídos pelas enfermeiras às mudanças de sua prática obstétrica, utilizando o método produção de sentidos no cotidiano - práticas discursivas, proposto por Mary Spink. Dados coletados por entrevista individual, semiestruturada, com 16 enfermeiras obstétricas, em maternidades públicas - Rio de Janeiro, Brasil. Foram analisadas com os conceitos de travessia de fronteiras e constelações de poder de Boaventura Santos. Os sentidos atribuídos pelas enfermeiras às práticas obstétricas evidenciaram uma transformação em processo no âmbito do conhecimento obstétrico e das práticas na perspectiva da desmedicalização. Fronteira, lugar de transição paradigmática de novas práticas surge em relações emancipatórias com as mulheres. Concluímos que experimentar novas práticas envolve superação dos limites conhecidos para encontrar autonomia, configurando-se um conhecimento e prática com possibilidades emancipatórias. Travessias, nessa direção, se dão pela ousadia de buscar e experimentar o novo, transgredir o limite e aproveitar os espaços abertos na constelação de poderes.

DESCRITORES: Saúde da mulher. Enfermagem obstétrica. Humanização do parto.

\section{OBSTETRICAL PRACTICE BY NURSES IN INSTIUTIONAL CHILDBIRTH: A POSSIBILITY FOR EMANCIPATORY KNOWLEDGE}

\begin{abstract}
This was a qualitative research project with the objective to analyze the meanings attributed by nurses to changes in their obstetrical practice, using the method "production of meanings in the everyday - discursive practices," as proposed by Mary Spink. Data was collected through semi-structured, individual interviews with 16 obstetrical nurses in public maternity wards in Rio de Janeiro, Brazil. The interviews were analyzed with the concepts "crossing boundaries" and "constellations of power," by Boaventura Santos. The meanings attributed by the nurses to the obstetrical practices verified a transformation process in the field of obstetrical knowledge, and practices in the perspective of demedicalization. The frontier, as a place of paradigmatic transition to new practices, emerges in emancipatory relationships with the women users of the service. We conclude that experimentation with new practices involves overcoming known limits to find autonomy, configuring a knowledge and practice with emancipatory possibilities. In this direction, crossings come from the boldness to seek and experiment the new, transgress the limit, and make use of open spaces in the constellation of powers.
\end{abstract}

DESCRIPTORS: Woman's health. Obstetrical nursing. Humanizing delivery.

\section{LA PRÁCTICA OBSTÉTRICA DE LA ENFERMERA EN EL PARTO INSTITUCIONALIZADO: UNA POSIBILIDAD DE CONOCIMIENTO EMANCIPATORIO}

\begin{abstract}
RESUMEN: Investigación cualitativa tuvo como objetivo analizar los sentidos atribuidos por las enfermeras en los cambios de su práctica obstétrica utilizando el método de producción de sentidos diariamente, propuesto por Mary Spink. Los datos fueron recolectados por medio de entrevista individual, semi-estructurada, a 16 enfermeras obstétricas en maternidades públicas - Rio de Janeiro, Brasil. Se analizaron los conceptos de trayecto de fronteras y constelaciones de poder de Boaventura Santos. Los sentidos atribuidos a las prácticas obstétricas evidenciaron una transformación en proceso del conocimiento obstétrico y sus prácticas en la perspectiva de la desmedicalización. La frontera, lugar de transición paradigmática de nuevas prácticas, donde surgen las relaciones emancipadoras con las mujeres. Concluimos que las nuevas prácticas involucran la superación de límites conocidos para encontrar autonomía. Las trayectorias ocurren por la audacia de buscar y experimentar lo nuevo, de transgredir el límite, y aprovechar los espacios abiertos en la constelación de poder.
\end{abstract}

DESCRIPTORES: Salud de la mujer. Enfermería obstetricia. Humanización del parto.

Texto Contexto Enferm, Florianópolis, 2013 Jul-Set; 22(3): 763-71. 


\section{INTRODUÇÃO}

No Rio de Janeiro, a introdução da enfermeira obstétrica na assistência ao parto hospitalar, implantada em 1988 na Secretaria Municipal de Saúde em uma de suas Maternidades, provocou um processo de ampliação desta assistência em várias outras, em um movimento de avanço e recuo trazendo implicações para o conhecimento e a prática profissional. A participação dessa profissional tem sido marcada por mudanças que acompanham a proposta de transformação das práticas na atenção ao parto normal, para um modelo assistencial menos intervencionista, em maternidades onde atua. $\mathrm{O}$ modelo excessivamente medicalizado de assistência ao parto vem sendo criticado mundialmente, o que culminou na avaliação sistemática das práticas obstétricas. Estes estudos geraram um conjunto de diretrizes e recomendações, com base em evidências científicas que a Organização Mundial de Saúde (OMS) vem adotando ao longo das últimas décadas. ${ }^{1}$ À luz dessas recomendações, o parto normal é considerado um evento fisiológico que necessita de apoio, avaliação e vigilância. As evidências apontam que para intervir neste processo deve haver uma justificativa realmente válida. ${ }^{2}$

Indicadores como a cobertura pré-natal e o acesso ao parto hospitalar melhoraram, porém, as taxas de mortalidade materna permanecem estáveis e em valores altos. As taxas de cesariana e mortalidade materna são incompatíveis com a tecnologia disponível, pois gestantes de baixo risco são submetidas a intervenções desnecessárias e as de alto risco recebem cuidado inadequado. ${ }^{3-4} \mathrm{O}$ modelo de humanização do parto e nascimento busca a formação de um novo arranjo de assistência, orientado pela segurança e eficácia dos procedimentos pela maior promoção dos direitos das mulheres, através de uma nova cultura assistencial e comunicacional entre os sujeitos envolvidos.

Na década de 1990, no município do Rio de Janeiro, houve a ampliação da experiência na operacionalização da Política de Humanização do Parto e Nascimento. Estabeleceu-se a hierarquização da assistência ao parto, atribuindo à enfermeira obstétrica a atenção direta aos partos de baixo risco. ${ }^{5}$ No Rio de Janeiro, tornou-se uma política pública vivenciada em um ambiente tenso, marcado pela disputa de espaço entre os profissionais da área obstétrica. Na busca de caminhos para superação das resistências, a enfermeira obstétrica, como agente estratégico na implantação de práticas do modelo humanizado em ambiente hospitalar, utilizou estratégias que viabilizassem sua inserção no cenário. Elaboraram projeto, investindo em capacitação e titulação das enfermeiras atuantes na instituição, discussão e divulgação dos resultados da assistência implementada, e estratégias de ampliação do contato com a gestante e sua família no pré-natal, compartilhando e construindo um conhecimento em parceria com as usuárias. ${ }^{6}$

As enfermeiras obstétricas têm apresentado uma disposição em desenvolver habilidades específicas, num modelo feminino e desmedicalizado, colocando em prática ações de humanização e desmedicalização do parto no âmbito da gerência, do ensino e do cuidado. ${ }^{7}$ Há um desafio colocado aos profissionais da área obstétrica de adequação técnica do modelo, com investimento em métodos de conforto e cuidados e o uso adequado dos avanços tecnológicos disponíveis e desejados. ${ }^{8}$ Dados consolidados das unidades da Secretaria Municipal de Saúde e Defesa Civil do Rio de Janeiro* apresentam resultados de 2007 a 2010, dos indicadores obstétricos e perinatais, mostrando os valores de partos realizados por enfermeiras obstétricas, em que as taxas de nascidos vivos no Município foram 29.881 (2008), 32.941 (2009) e 32.626 (2010). A proporção de partos atendidos por enfermeiras obstétricas anualmente foi de $23.8 \%$ em 2008, de 19,0\% em 2009 e, no primeiro semestre de $2010,21,7 \%$ do total de partos realizados nas seis unidades referidas. Vale ressaltar que a participação da enfermeira nessa assistência, tem mostrado um percentual significativo na atenção ao parto normal, com a proposta de intervenção mínima no processo da parturição.

Considerando este contexto, selecionamos a questão norteadora: quais os sentidos atribuídos pela enfermeira à prática obstétrica na assistência ao parto? A pesquisa teve como objetivo analisar e discutir os sentidos atribuídos pelas enfermeiras obstétricas à sua prática de atenção ao parto.

\section{METODOLOGIA E CONCEITOS TEÓRICOS}

Pesquisa qualitativa e social que possibilitou mergulhar no caminho do pensamento discutido por Spink, buscando a produção de sentidos

* Fonte: Superintendência de Maternidades da Secretaria Municipal de Saúde e Defesa Civil do Rio de Janeiro, 2010. 
no cotidiano, por meio das práticas discursivas, o que determinou a escolha do referencial metodológico, em consonância à problemática e ao objeto desse estudo. ${ }^{9}$

A produção de sentidos no cotidiano é uma abordagem teórico-metodológica para análise de práticas discursivas em pesquisas qualitativas. ${ }^{10}$ O sentido é considerado um constructo social, coletivo e interativo, onde a dinâmica das relações sociais constroem a linguagem que compreendem os fenômenos experimentados no cotidiano. A produção de sentido é entendida como um fenômeno sociolinguístico, uma vez que o uso da linguagem fornece sustentação às práticas sociais geradoras de sentido. Busca-se entender as práticas discursivas que atravessam o cotidiano como narrativas, argumentações, conversas e os repertórios utilizados nessas práticas discursivas.

A coleta de dados ocorreu de agosto a novembro de 2010, e foram sujeitos 16 enfermeiras obstétricas atuantes nos seis cenários selecionados, convidadas à produção de sentidos, utilizando a técnica de entrevista individual e semiestruturada. Como critério de inclusão deveriam ter 10 anos ou mais de assistência ao parto institucional, caracterizando experiências na área. Para colocar em evidência a compreensão do que relataram as participantes em seus depoimentos, utilizamos os conceitos de Spink ${ }^{9}$ na organização das entrevistas e obtenção das categorias analíticas. A construção do roteiro de entrevista mostra que as questões elencadas buscaram evidenciar a prática obstétrica da enfermeira na assistência ao parto, no contexto de vida e da profissão aos quais estão inseridas, apresentando os motivos para escolha da área de atuação e como atribuem sentidos às travessias de sua prática obstétrica. Esta estratégia permitiu entender a dinâmica das trocas discursivas e analisar os temas que foram prioritários para o alcance dos objetivos de pesquisa, além de dar uma visão do conjunto. ${ }^{9}$

Neste movimento interpretativo surgiram os eixos teóricos de análise, baseados nos conceitos do sociólogo Boaventura Santos, ${ }^{11}$ travessia de fronteiras e constelações de poderes. Este autor analisa as estruturas sociais considerando a modernidade ocidental como um paradigma fundado na tensão regulação e emancipação social. Nessa perspectiva existe um intervalo nas sociedades e culturas contemporâneas. Este intervalo possui um movimento que se situa na transição entre o paradigma dominante e um paradigma emergente; estamos localizados em um período de transição paradigmática a caminho de um outro paradigma. ${ }^{11}$

A transição paradigmática se apresenta em duas dimensões principais: a epistemológica e a societal. As duas transições são autônomas, porém relacionadas, pois formas alternativas de conhecimento geram práticas sociais alternativas. O grande mediador entre o conhecimento e a prática é a subjetividade que une as duas transições. A ação transformativa proposta na transição paradigmática produz relações sociais onde desafios precisam ser superados e, neste espaço, intervalar os conceitos de Boaventura, de constelações de poderes e travessia de fronteiras, nos auxiliaram a produzir a análise das subjetividades que emergiram dos dados que, como o autor nos aponta, são o ponto de união entre as duas dimensões dessa transição epistemológica e societal. ${ }^{11}$

Nas práticas analisadas há uma constelação de poderes nos espaços institucionais que funcionam autonomamente, mas possuem interseções, influenciando a realidade dentro de grandes estruturas como o Sistema Único de Saúde, sua gestão nacional e local, as instituições de ensino profissional, em suas dimensões de ensino, extensão e pesquisa, constituindo relações instáveis que ora estimulam a participação dos agentes institucionais, ora recuam na oferta de possibilidades.

O mesmo autor refere que "nenhuma transformação paradigmática será possível sem a transformação paradigmática da subjetividade". 11:333 Com isto, nos apresenta mapas da transição paradigmática, nomeados como emancipações. Prossegue dizendo que a subjetividade emergente tem prazer em viver na fronteira, que surge como uma forma privilegiada de sociabilidade.

O cenário de pesquisa foi composto pela Casa de Parto David Capistrano Filho e em cinco maternidades públicas do Município do Rio de Janeiro. A pesquisa foi aprovada pelo Comitê de Ética da Secretaria Municipal de Saúde e Defesa Civil-RJ, através do parecer n. 192 A, em 10 de agosto de $2010 .^{12}$

\section{RESULTADOS E DISCUSSÃO}

Das 16 enfermeiras obstétricas que participaram da pesquisa, 13 eram do sexo feminino e três do sexo masculino, em idades que variaram de 38 a 57 anos. Quando falaram sobre sua formação profissional informaram sobre seu interesse em atuar na área obstétrica desde a conclusão da graduação, e só foram atuar na assistência ao 
parto em torno de 12 anos após a sua formação básica, apontando a falta de oportunidade e não de interesse nesta atuação.

Dentre as ações propostas para romper a lógica intervencionista de assistência ao parto normal, apresentam estratégias como a mudança do ambiente dos centros obstétricos para centros de parto normal intra ou extra-hospitalar, além das casas de parto comunitárias. Nestes ambientes existe uma produção de conhecimento centrado no protagonismo da mulher transformando as relações entre profissionais e usuárias. A inserção das enfermeiras obstétricas nos cenários tradicionais das maternidades provocou um desequilíbrio na ordem estabelecida. Reconhecemos estes espaços como de transição paradigmática e consideramos o centro obstétrico tradicional onde prevalece o conhecimento-regulação, que se desdobra em um modelo de assistência regulado pela medicalização.

\section{A fronteira: estabelecendo relações com as formas de conhecimento e práticas congela- das; travessias entre teoria e prática}

Os sentidos atribuídos pelas enfermeiras, nos discursos sobre suas práticas no cotidiano da assistência ao parto, desenham o espaço de fronteira. Lugar da transição paradigmática, de onde surgem as oportunidades de práticas emancipatórias. Este movimento é de tensão, pois investe contra a ordem instituída, onde surgem limites de ordem externa e outros de ordem interna nas relações entre profissionais, com a clientela, e mediado pelo conhecimento, que precisam ser ultrapassados na direção de um modelo emergente.

Um dos sentidos apresentados pelas depoentes do estudo foi o confronto entre o conhecimento adquirido no modelo biomédico e as experiências do cotidiano da prática, verificando que as mudanças no cuidado à mulher parturiente são necessárias: a gente muda a cada dia. Agora eu creio que são pequenos detalhes, porque a ideia principal já encontrei, há algum tempo. No início, começamos muito influenciados pelo modelo biomédico. Ainda fazíamos episiotomia; honestamente, eu ainda não tinha sido sensibilizada o suficiente para começar essa prática sem episiotomia, não. No decorrer do tempo eu comecei a perceber que não tinha necessidade, e isso foi a prática aliada a tudo que a gente vinha recebendo de informação. Queria participar, absorver toda aquela informação nova, e isso, somado à prática, foi realmente um agente transformador (E3).
A ruptura epistemológica, na ciência pósmoderna, é um importante salto do conhecimento científico para o senso comum. Os conhecimentos são aprendidos através de múltiplas fontes e transmitidos a tantas outras, sem distinções. ${ }^{13}$ Podem vir a ser um novo senso comum, com mais sentido, ainda que menos comum. ${ }^{14}$

Buscamos explorar os cenários de nascimento pesquisados como espaços de fronteira para refletir as subjetividades emergentes provocadas por esse contexto, com a finalidade de encontrar os sentidos atribuídos pelas enfermeiras à sua prática e o potencial de mudanças, conforme as expressões abaixo:

[...] hoje eu me considero uma profissional transformada. No início eu aprendi muita coisa, e não tinha noção alguma. Não gostava do que via na prática, $e$ tentei buscar pessoas e conhecimentos diferenciados daquilo que eu via. Mesmo quando eu estava na maternidade $X$, com toda a proposta de humanização, a gente ainda via muita coisa, e paralelo a isso, a gente tinha uma vontade de fazer diferente. Nós éramos um grupo com uma visão muito diferenciada, e começamos a buscar propostas diferentes de assistir ao parto, de acompanhá-lo, enfim. Eu via uma mulher muito violentada naquele meio, e eu queria uma coisa diferente, não queria fazer aquelas mesmas coisas. Aquilo, de alguma forma, também me violentava. Eu não queria mais ver aquelas reduções de colo, não queria ver Kristeller e não queria fazer também (E4).

O movimento da travessia em direção a uma prática menos intervencionista dá início à invenção de um processo de emancipação onde a autonomia e o amadurecimento se apresentam como um argumento construído no processo de enfrentamento de um conhecimento colonizador, ${ }^{11}$ que começa a ser substituído por outro conhecimento, no espaço da fronteira: ah! muita, muita mudança. A gente amadurece, a gente vai amadurecendo junto, vai amadurecendo como pessoa, então a sua experiência vai te dando segurança; a sua segurança ajuda a realizar um trabalho melhor, a sua segurança faz com que você aborde a mãe de uma maneira mais efetiva e afetiva. Acho que é amadurecimento pessoal junto ao amadurecimento profissional. Isso para mim gera muita mudança (E11).

Para compreender a reflexão crítica proposta, torna-se necessário uma atitude que recusa o conformismo e a resignação diante de características da realidade que são apresentadas, exigindo uma disposição de lutar por alternativas. ${ }^{15}$ Nessa reflexão consideramos que a compreensão da ruptura epistemológica seja possível, ao buscar apreender as transformações contidas nessa realidade. 
Ao habitar na fronteira é inevitável um balanço entre o que de antigo permanece e o que deve ser abandonado. Uma característica do uso seletivo de tradições é escolher do seu passado aquilo que deseja reter e o que deseja esquecer ou modificar, mas é viver num tempo entre os tempos às situações novas; por vezes subvertem os planos e previsões, levam à criação e à necessidade de aproveitar as oportunidades nas situações de desespero, o que nos leva a recorrer a tudo que nos pode salvar. A subjetividade da transição paradigmática é aquela para quem o futuro é uma questão de vida ou morte. ${ }^{11}$ A ruptura é um tempo de morte que traz o novo à luz; algumas vezes com dor, como nos mostra a depoente:

[...] o que me desafiou de fato foi entender que dentro da maternidade, por mais que eu tivesse conhecimento, eu não era ninguém, haviam muitas limitações, faltava autonomia, ou faltava o poder de decidir com a mulher. Aquilo foi me deixando [...] desesperada é o termo, porque você o tempo inteiro está sendo questionada, tendo que rebater, muitas vezes você fazia isso tudo e passavam por cima de você, como um trator. Eu comecei a entender que aquele espaço não era mais meu e se eu quisesse continuar nesse modelo, nessa forma diferente, já não tinha como voltar, porque eu já não acreditava naquilo, eu ia ter que pular aquela linha. Voltar não era a opção. Eu não tinha opção, ou era mudar internamente e caminhar de outra forma, ou era nem sei, era morrer pra obstetrícia. Eu acho que era morrer pra obstetrícia, porque eu não ia conseguir fazer daquela forma, continuar daquele outro jeito e me sujeitando. Não sei se eu teria desistido! Isso eu acho agora, mas eu não sei como é que seria, poderia ter tido até outro rumo, mas nesse momento aquilo foi o que me motivou (E16).

Instalam-se as condições para a busca da mudança. A oferta da possibilidade acena e embora o que se deseja como futuro ainda não se mostre com clareza, a provocação aponta o que não queremos.

As enfermeiras demonstraram em seus discursos a necessidade de aprofundamento teórico para realizar mudanças de atitudes na prática, como uma travessia entre teoria e prática e as relações entre ambas. As subjetividades que surgem da transição paradigmática delineiam o espaço de fronteira habitado. $\mathrm{Na}$ exploração das subjetividades apresentam-se as práticas emancipatórias, que são formuladas considerando e partilhando com a mulher usuária em uma relação emancipatória para ambas. As contradições e o potencial criativo no espaço de fronteira são as condições para transgressão dos limites, onde a morte está presente e a chegada à outra condição é necessária para mudança da prática obstétrica, e tal situação depende da força gerada pela energia da inquietação e da concepção de alternativas sociais para negociar na constelação de poderes.

Neste sentido, entendemos as práticas experimentadas pelas enfermeiras obstétricas e pelas mulheres como uma possibilidade da emergência de um conhecimento emancipatório, como nos exemplifica a depoente: não há outra fórmula; acho que é o nosso objeto de trabalho a mulher que assistimos mesmo. Quando eu oriento as mulheres, passo conhecimento, isso me deixa muito feliz. Eu procuro falar pra elas sobre as práticas, porque já vivenciei, mas com a alma também. Eu entendi que o parto é um ato fisiológico (E3).

"Hoje o objeto é a continuação do sujeito por outros meios. Por isso, todo conhecimento emancipatório é autoconhecimento, ele não se descobre, cria" ${ }^{11: 83}$ A relação conhecimento prática emancipatória pressupõe uma concepção de sujeito/objeto construída pela ciência moderna. ${ }^{13}$

\section{Modos de funcionamento das constelações de poderes: fixam fronteiras ou abrem-se para novos caminhos}

Entendemos que uma complexa teia é tecida quando as práticas obstétricas das enfermeiras desenrolam-se em processos de transformação e vão delineando em práticas discursivas as relações sociais tensas, que refletem um espaço de transição paradigmática. Os desafios se apresentam e emerge o silenciamento do conhecimento, por uma constelação de poderes, mostrando que a tarefa é complexa. Remete-nos ao que entendemos como poder em suas múltiplas facetas e permitindo que estas se expressem, tomem forma e, no ato, no acontecimento indiquem uma opção pelo caminho a seguir; a distinção é valorizada.

Mergulhando na ideia de que as ações acontecem em um espaço chamado fronteira, instável, desconhecido, que abandona a tradição, o poder que cada um possui ou que está submetido tende a ser exercido mais no modo abertura-de-novos-caminhos, do que no modo de fixação de fronteiras. Isto porque a sociabilidade e a subjetividade da fronteira estão pautadas em limites, e a transgressão desses limites tem como base a complexidade, pois as possibilidades são múltiplas. As relações se dão no encontro entre usuárias e profissionais do cuidado, e entre os profissionais e suas formas de cuidar e tratar. "Nas constelações de poder, os diferentes tipos de poder competem entre si 
para serem ativados num modo de alta-tensão, o que torna as constelações instáveis, imprevisíveis e afeitas a explosões, ora destrutivas e ora criativas". ${ }^{11: 351}$

As participantes nos contam suas experiências e nos apresentam as formas cotidianas de executar sua prática. Destacamos aqui uma fala dentre várias, que ajudará na reflexão dessa análise. A entrevistada nos descreve acontecimentos, exemplificando suas decisões por uma prática que julga adequada ao momento à usuária, narrando o seu contexto. Realizar ou não uma episiotomia era o que estava em questão e, ao descrever a cena, nos contou que durante o atendimento de uma usuária, a qual estava acompanhando e, naquele momento, encontrava-se na fase expulsiva do bebê, um dos médicos da equipe do plantão entrou com os alunos de medicina que o acompanhavam em visita, e começou a narrar os passos que a enfermeira daria a cada momento, antes que ela os fizesse. Ele dizia: [...] 'ela vai fazer a antissepsia, vai colocar os campos, agora vai fazer anestesia e, seguida, a episiotomia' [...]. Segue a enfermeira nos contando: e eu não fiz, nem anestesiei, nem fiz episiotomia, $e$ eles se olharam. Houve um silêncio e um clima sério, e ele deu uma explicação para os alunos, dizendo que as enfermeiras, às vezes, não fazem episiotomia, mas não se dirigiu à mim; me senti pressionada no momento, mas não senti vontade de fazer episio, de fato não precisava, e não fiz, e o bebê nasceu, e nasceu muito bem [...] (E10).

Ao narrar o acontecimento, o sentido apresentado pela enfermeira expressava que se sentia segura e confiante em sua prática, era conhecida, e fluía independente, maior que a pressão que poderia fazê-la hesitar e duvidar de sua avaliação. O que pode parecer muito simples é a ilustração da complexidade que envolve o momento da decisão por uma prática e o longo caminho que percorremos quando se trata de uma prática com base no conhecimento científico e nas relações que as fazem acontecer no cotidiano. Neste caso, ainda não surge a voz da mulher, que poderia influenciar e dizer quais as intervenções que seriam aceitáveis em seu corpo. Mas nas constelações de poderes focamos o olhar na competência do profissional para o exercício dessa prática, de forma mais autônoma e decisória.

Neste contexto, o problema central é como imaginar uma subjetividade suficientemente apta para compreender e querer a transição paradigmática, e transformar a inquietude em energia emancipatória; uma subjetividade que queira se empenhar nas competições paradigmáticas, quer no nível epistemológico quer no nível societal, para conferir uma credibilidade crescente ao novo paradigma, por muito provisória e reversível que ela seja. ${ }^{11}$

Nessa perspectiva, as relações do cotidiano são expressas com enfrentamentos e são entendidos como obstáculo a ser superado. É o que observamos no depoimento a seguir:

bom, em uma instituição hospitalar, os desafios permanecem praticamente os mesmos. É o enfrentamento da medicalização mesmo, o enfrentamento da corporação; é a relação com tudo isto, é uma relação com a maioria. Esta maioria são os nossos colegas médicos que fazem questão da cultura hospitalar e de colegas enfermeiras, também, que discursam muito, mas na prática não é bem assim, mas faz um discurso que agrada e que as pessoas até acreditam, então isto também irrita. Aí eu penso, que tá bom do jeito que eu estou, eu estou até muito bem. Mas não sou milagrosa, o que é isto [ser milagrosa]? É o imaginário da enfermeira do parto humanizado, é a transformação da super-enfermeira, é aquela que consegue, em um universo deste, fazer um trabalho como aquele que a gente imagina, trazer um imaginário para uma realidade tão endurecida e tão hegemônica. Eu acho que é fazer milagre! (E1).

Trata-se de um ponto desafiador trazer para realidade o conhecimento e a prática transformada e encontrar espaço no pensamento e na prática hegemônica hospitalar. Uma determinada relação emancipatória, para ser eficaz e não conduzir à frustração, precisa se integrar em uma constelação de práticas e relações emancipatórias. ${ }^{11}$

Para que estas relações emancipatórias se estabeleçam em constelações devem ser estimuladas e favorecidas em espaços onde possam se ancorar. Encontrar estes espaços também é um desafio, e por meio dessas relações, podemos reconhecer a variabilidade da constelação de poderes que estruturam a política local, a academia e seu lugar de saber, além de grupos que podem elencar seus interesses, onde sabemos que estas relações, por envolver desigualdades materiais e imateriais são instáveis, ora estimulam a participação e ora recuam na oferta de oportunidades, como depõe a enfermeira a seguir: eu acho que o desafio é você tentar se manter nessa rotina estressante. Porque chega uma hora que você cansa. Você acredita, você aposta num modelo, e aí você começa a procurar estratégias. Eu sou assim, quando eu tô passando por alguma situação que está me incomodando, eu não sei viver naquele incômodo, eu tenho que otimizar alguma estratégia, pra eu não sofrer; então se alguma coisa está me incomodando muito, eu vou tentar mudar. Eu 
não vou ficar reclamando a vida toda, como eu vejo as pessoas reclamando a vida toda. Eu não sei fazer isso, eu tenho que dar um jeito de modificar (E10).

Por outro lado, medir desigualdades de trocas desiguais não é fácil, pois as relações de poder não acontecem de forma isolada, mas na sequência ou em constelações. Estas constelações se configuram em um conjunto de relações entre pessoas e grupos sociais que não são totalmente previsíveis. ${ }^{11}$ A busca de igualdade é favorecida com a oferta de oportunidades, mas é importante que os grupos saibam expressar seus interesses, tenham um projeto coletivo nos vários âmbitos que, ao apresentar sua distinção, também mostre suas diferenças; o que é prioridade para um determinado grupo pode não ser para o outro.

A enfermeira vai apresentando a maneira pela qual, no cotidiano, busca vencer o modo limitador da relação de poder, para encontrar espaço em que seja considerada, buscando sua distinção, como neste depoimento: me desafiou e me desafia até hoje. Foi diferenciar a atenção que é dada à parturiente pelo médico, do atendimento que é dado pela enfermeira. Isso me impulsionou muito. Mostrar que a gente consegue fazer um trabalho diferenciado. Esse atendimento é gritantemente melhor, não estou diminuindo o trabalho de ninguém, mas eu acho que o médico não faz trabalho de beira de leito, e parturiente, de parto normal, de baixo risco, precisa de beira de leito, precisa de massagem nas costas, precisa de companhia para o banho, precisa de conversa, precisa respirar, andar, sentar, e é isso que impulsiona. Conseguir demonstrar a nossa capacidade de prestar um bom atendimento (E11).

Mensurar as desigualdades é também avaliar até que ponto e de que maneira elas afetam as condições de vida e trabalho, além da trajetória das pessoas envolvidas no espaço em que se constituem as relações. A capacidade dos grupos em organizar seus interesses para participar com autonomia dos processos nos quais estão implicados pode abrir espaços nas constelações de poderes. Os modos de funcionamento das relações de poder apontam um dualismo que revela um duplo caráter nos seus pólos, exemplificados pelo possível e impossível, pensável e impensável, desejado e indesejado, legítimo e ilegítimo.

O que faz uma relação social transformarse em exercício de poder é a forma com que são tratados os interesses das partes na relação, e do dualismo apresentado, que tanto pode fixar as fronteiras, sendo inibidor de expressões diferentes, ou permissor, modo abrir caminhos e ampliar espaços promovendo mais igualdades e colocando o poder como relacional nas possibilidades de potenciar ou despotenciar. ${ }^{11}$

É importante criar espaços e redes em que se torne uma condição o exercício do diálogo aberto e honesto, para evidenciar as interfaces de conhecimento entre profissionais e serviços. Nesses espaços, construir, em parceria, um sistema de resolução de conflitos, onde estejam estabelecidos com clareza o respeito aos limites. ${ }^{16}$ Os fatores que influenciam nessa constituição apontam para uma atitude individual positiva, o suporte oferecido pela estrutura institucional e a avaliação permanente de recursos e resultados para uma prática condizente com as características da demanda das mulheres assistidas.

O rompimento varia com o contexto, o momento que pode ser sutil ou com embates. $\mathrm{O}$ contexto também é constituinte e decisivo na conformação da realidade de saúde e as possibilidades emancipatórias emergem da fricção destes agentes e sua capacidade de negociação interna e externa com essa realidade. Quando surge no contexto das constelações, no sentido de ampliar as ofertas de oportunidades, somado a decisão de mergulhar na oportunidade, pode contribuir para tornar o possível, onde parecia impossível.

\section{CONCLUSÃO}

Considerando o objeto e objetivos propostos para analisar os sentidos atribuídos pelas enfermeiras às mudanças de sua prática obstétrica, obtivemos, por meio dos conceitos de travessias de fronteiras e constelações de poder, utilizado no referencial teórico de análise, resultados que produzem reflexões sobre a prática obstétrica da enfermeira.

Experimentar uma nova prática envolve uma superação dos limites conhecidos para encontrar a autonomia, configurada por um conhecimento e prática com possibilidades emancipatórias. Os atores sociais do estudo descrevem travessias na direção de um conhecimento e práticas desconhecidos, com várias motivações e questionamentos com as experiências vividas nesse cenário. As travessias, nessa direção, inicialmente desconhecidas, aparentemente se dão pela ousadia de buscar e experimentar o novo e transgredir o limite; ressignificar a abordagem provoca novas experiências e configura outra realidade e outros limites.

Com o propósito de analisar os sentidos atribuídos pelas enfermeiras à sua prática e o potencial de mudanças entre contradições e hesi- 
tações, encontramos nesses resultados um desejo de mudanças e a busca para concretizá-las gerou espaços nas constelações de poder. As participantes dessa pesquisa estabelecem relações com o contexto dos macroprocessos, representados pelas estratégias como a mudança do ambiente do centro obstétrico para o centro de parto normal intra ou extra-hospitalar, produzindo um conhecimento centrado no protagonismo da mulher. Estas ações, quando concretizadas nas instituições em nível local, na qual estavam inseridas em microprocessos, formularam uma trama de relações locais. Ao conquistar o sucesso mensurado pela satisfação da usuária e da própria enfermeira, experiências práticas mostraram as evidências científicas. Estas favoreceram a confiança através de novas experiências práticas, gerando mudanças e possibilidades de aprofundar nas escolhas e amadurecer como profissional, capaz de repensar sua prática e valorizar a produção de saberes no cotidiano da prática obstétrica.

Pensar em um espaço geográfico como a fronteira, nos auxiliou na reflexão e análise do contexto da travessia entre a teoria e a prática como um espaço de transição paradigmática. Possibilitou dar significado às experiências existenciais, quase sempre contraditórias, intensas e no limite, de forma individual ou coletiva. Entendê-las como uma forma privilegiada de sociabilidade nos pareceu uma contradição. Entretanto, nos diferentes cenários, estar à margem da prática obstétrica convencional não significa viver uma vida marginal, mas é uma provocação que pode guiar a exploração das possibilidades e desejar tornar a margem em centro, ou deixar a margem e voltar ao centro, em movimento constante de autonomia e dependência, benefícios e riscos, aproximação e afastamento.

Neste contexto, constituir novos sujeitos implica que não sejam resignados com as situações insatisfatórias o tempo todo, que não tenham a arrogância de mudar o mundo, mas a clareza de buscar e aproveitar os espaços abertos na constelação de poderes para interagir com uma constelação de saberes.

Nestes processos estão presentes elementos que ao mesmo tempo em que parecem ser restritivos a partir da reflexão de encontrar mais saídas, quer individualmente ou em grupo, ampliam-se e configuram-se mais espaços na constelação de poderes em disputa, tornando-se evidente a competência e a confiabilidade para enfrentar os desafios neste campo profissional.

\section{REFERÊNCIAS}

1. World Health Organization (WHO). Care in normal birth: a practical guide. maternal and newborn health/ safe motherhood unit. Geneva: WHO; 1996.

2. Ministério da Saúde (BR), Secretaria de Políticas de Saúde, Área Técnica de Saúde da Mulher. Parto, aborto e puerpério: assistência humanizada à mulher. Brasília (DF): MS; 2001.

3. Diniz SG. Gênero, saúde materna e o paradoxo perinatal. Rev Bras Crescimento e Desenvolvimento Humano. 2009 Ago; 19(2):313-26.

4. Dias MAB, Deslandes SF. Expectativas sobre a assistência ao parto de mulheres usuárias de uma maternidade pública do Rio de Janeiro, Brasil: os desafios de uma política pública de humanização da assistência. Cad Saúde Pública. 2006 Dez; 22(12):2647-55.

5. Dias MAB, Domingues RMSM. Desafios na implementação de uma política de humanização da assistência hospitalar ao parto. Ciênc Saúde Coletiva. 2005 Jul-Set; 10(3):669-705.

6. Oliveira Mouta RJ, Progianti JM. Estratégias de luta das enfermeiras da Maternidade Leila Diniz para implantação de um modelo humanizado de assistência ao parto. Texto Contexto Enferm. 2009 Out-Dez; 18(4):731-40.

7. Vargens OMC, Progianti JM, Silveira ACF. O significado de desmedicalização da assistência ao parto hospitalar: análise da concepção de enfermeiras obstétricas. Rev Esc Enferm USP. 2008; 42(2):339-46

8. Carraro TE, Knobel R, Radünz V, Meincke SMK, Fiewski MFC, Frello AT, et al. Cuidado e conforto durante o trabalho de parto e parto: na busca pela opinião das mulheres. Texto Contexto Enferm. 2006; 15 (Esp):97-104.

9. Spink MJ organizadora. Práticas discursivas e produção de sentidos no cotidiano: aproximações teóricas e metodológicas. $3^{a}$ ed. São Paulo (SP): Cortez; 2004.

10. Medrado B, Spink MJ. Produção de sentidos no cotidiano: uma abordagem teórico- metodológica para análise de práticas discursivas. In: Spink MJ, organizador. Práticas discursivas e produção de sentidos no cotidiano: aproximações teórico-metodológicas. $3^{\text {a }}$ ed. São Paulo (SP): Cortez; 2004. p. 41-61.

11. Santos, BS. Para um novo senso comum: a ciência, o direito e a política na transição paradigmática, $\mathrm{V}$ 1- A crítica da razão indolente: contra o desperdício da experiência. $7^{a}$ ed. São Paulo (SP): Cortez; 2009.

12. Ministério da Saúde (BR), Conselho Nacional de Saúde. Resolução n. 196 de 10 de outubro de 1996: diretrizes e normas regulamentadoras de pesquisa envolvendo seres humanos. Brasília (DF): MS; 1996.

13. Santos BS. Um discurso sobre as ciências. $6^{\mathrm{a}}$ ed. Porto (PT): Afrontamento; 1993. 
14. Teixeira E. Cartografia simbólica do cuidado. reflexões à luz do pensamento de Boaventura de Souza Santos. São Paulo (SP): Martinari; 2008.

15. Mattos RA. Integralidade, trabalho, saúde e formação profissional: algumas reflexões críticas feitas com base na defesa de alguns valores. In: Matta GC, organiza- dor. Estado, sociedade e formação profissional em saúde: contradições e desafios em 20 anos de SUS. Rio de Janeiro (RJ): FIOCRUZ/EPSJV. 2008, p. 313-52.

16. Downe S, Finlayson K, Fleming A. Creating a collaborative culture in maternity care. J Midwifery Womens Health. 2010 May-Jun; 55(3):250-4. 